\title{
Studies in laboratory animals to assess the safety of anti-inflammatory agents in acute porphyria
}

\author{
KENNETH E L McCOLL, GEORGE G THOMPSON, AND \\ MICHAEL R MOORE
}

From the University Department of Medicine, Western Infirmary, Glasgow

\begin{abstract}
SUMMARY The safety of various anti-inflammatory drugs in acute porphyria was assessed by examining their effect on rat hepatic haem synthesis. Azapropazone, chloroquine, and golds increased $\delta$-aminolaevulinic acid (ALA) synthase activity, indicating that they are liable to precipitate porphyric crises. Aspirin, ibuprofen, indomethacin, ketoprofen, flurbiprofenis phenylbutazone, naproxen, prednisolone, and penicillamine did not increase ALA synthase activity and should be safe in porphyria. Though these animal studies can be used as a guide tor prescribing in patients with acute porphyria, some caution is still required as species may vary in their response to inducing agents.

Key words: chloroquine, azapropazone, gold, $\delta$-aminolaevulinic acid synthase.
\end{abstract}

The acute hepatic porphyrias which comprise acute intermittent porphyria, hereditary coproporphyria, and variegate porphyria are examples of pharma-

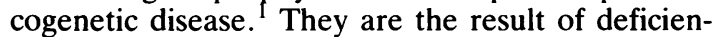
cies of individual enzymes in the pathway of haem biosynthesis and are inherited in an autosomal dominant fashion. ${ }^{2}$ Subjects with the genetic trait generally enjoy good health but are at risk of developing severe and life threatening attacks of porphyria if exposed to certain commonly prescribed drugs. Prevention of such attacks depends upon identifying subjects with the genetic trait and preventing them from being exposed to porphyrinogenic drugs. As a result of family screening programmes there has been a marked increase in the number of subjects known to have porphyria and a significant proportion of them will require treatment with anti-inflammatory agents at some time in their life. To provide some guidance concerning their safety in patients with porphyria we have tested 12 commonly prescribed anti-inflammatory agents in laboratory animals.

\section{Materials and methods}

The porphyrinogenicity of the drugs was tested by examining their effects on the activity of the rate

Accepted for publication 5 March 1987.

Correspondence to Dr Kenneth E L McColl, University Department of Medicine, Western Infirmary, Glasgow G11 6NT. controlling enzyme of haem biosynthesis aminolaevulinic acid (ALA) synthase in rat hepatio tissue. To confirm the reliability of the animat model, phenobarbitone was also tested. For each drug examined six male Sprague-Dawley rats reo ceived the test drug and six control rats received the appropriate placebo solution. The drugs were admi nistered intraperitoneally for three days in a dosage equivalent to 2.5 times the normal human dosage expressed as $\mathrm{mg} / \mathrm{kg}$ body weight/day. The animals were killed three hours after the final injection, thei livers excised, and the activity of hepatic ALA synthase determined as previously described. ${ }^{3}$ Sta tistical comparisons of the test and control animals were performed using the non-parametric Mann? Whitney $\mathrm{U}$ test.

\section{Results}

The effects of the various drugs on hepatic ALA synthase activity are shown in Table 1 . Phenobarb tone resulted in a $214 \%$ increase in enzyme activit $(p<0 \cdot 01)$. Of the eight first line non-steroidal ante inflammatory drugs studied, only azapropazon $₫$ significantly affected ALA synthase activity, increasi ing it by $55 \%(p<0.05)$. Of the four second line agents studied, gold increased ALA synthase activit产 by $56 \%(p<0.05)$ and chloroquine increased it b $71 \% \quad(p<0.05)$. ALA synthase activity was nof affected by prednisolone or penicillamine. 
Table 1 Effect of anti-inflammatory agents and phenobarbitone on hepatic ALA synthase activity in rats

\begin{tabular}{llc}
\hline Drug & $\begin{array}{l}\text { Dose } \\
(\mathrm{mg} / \mathrm{kg} / 24 \mathrm{~h})\end{array}$ & $\begin{array}{l}\text { Hepatic ALA synthase } \\
\text { activity } \\
\text { change from control })\end{array}$ \\
\hline Phenobarbitone & 10 & $+214(\mathrm{p}<0 \cdot 01)$ \\
Aspirin & 80 & $+31 \quad$ \\
Azapropazone & 50 & $+55(\mathrm{p}<0 \cdot 05)$ \\
Flurbiprofen & 15 & -23 \\
Ibuprofen & 40 & +4 \\
Indomethacin & 10 & -3 \\
Ketoprofen & 10 & +10 \\
Naproxen & 30 & -6 \\
Phenylbutazone & 20 & -14 \\
Prednisolone & 4 & 0 \\
Chloroquine & 25 & $+71(\mathrm{p}<0 \cdot 05)$ \\
Gold (sodium & & \\
$\quad$ aurothiomalate) & $0 \cdot 5$ & $+56(\mathrm{p}<0 \cdot 05)$ \\
Penicillamine & 20 & +8 \\
\hline
\end{tabular}

\section{Discussion}

Unfortunately, there is no totally reliable way of determining which drugs are safe and unsafe in patients with acute porphyria. ${ }^{4}$ Testing drugs by administering them to patients with porphyria is clearly unethical, and human data therefore depend on anecdotal reports of the effect of treatment of intercurrent diseases in patients with the genetic trait. Such anecdotal reports are difficult to interpret as several drugs have often been prescribed simultaneously, and the intercurrent disease, rather than the drugs, may have triggered the porphyria attack. In addition, only a proportion of patients with porphyria will develop attacks on exposure to porphyrinogenic drugs and anecdotal reports of safety may be misleading. Owing to the rarity of the acute porphyrias and the vast number of prescribable drugs, anecdotal reports only provide very limited information about the safety of drugs in this disease.

The elucidation of the underlying biochemical defect in the acute porphyrias has shown new ways of predicting the effect of drugs on the disorder. Patients with acute porphyria have partial deficiencies of individual enzymes in the pathway of haem biosynthesis. As a consequence there is a compensatory increase in the activity of the initial and rate controlling enzyme of the pathway ALA synthase, resulting in varying degrees of overproductions of porphyrins and porphyrin precursors formed before the enzyme block. Drugs which can precipitate porphyric crises in these patients do so by further increasing ALA synthase activity, and therefore the safety or otherwise of a drug in acute porphyria can be checked by assessing its effect on this enzyme. Ideally, drugs should be tested by assessing their effect on hepatic ALA synthase activity in humans, but this would involve repeated liver biopsies and is again unethical. Consequently, the porphyrinogenicity of drugs is tested by assessing their effect on hepatic ALA synthase in laboratory animals. This method is not totally reliable as there may be slight differences between species in their response to drugs, ${ }^{5}$ but currently it is the best available method. In our own clinical practice with patients with porphyria we have found the animal studies a valuable means of guiding our clinical prescribing.

In the animal studies the drug is administered in a dose which is slightly higher than the human dose as false negative results are potentially more damaging to the patients. The drugs are administered to animals by intraperitoneal injection as we have found this to be the only reliable way of being certain that the full dose has been received. Hepatic ALA synthase activity is measured three days after the initial dose as this is the time at which any increase in the enzyme activity will be most marked. ${ }^{6}$ The inclusion of a porphyrinogenic drug, such as phenobarbitone, in the animal studies provides confirmation of the validity of the model and also permits some measurement of the porphyrinogenicity of the drugs being tested relative to the standard.

The finding that azapropazone, chloroquine, and gold increase hepatic ALA synthase activity indicates that these drugs are liable to result in exacerbations of acute porphyria. The degree of increase in enzyme activity with these drugs was less than with phenobarbitone, indicating that they are less potent porphyrinogenic agents. The other drugs tested did not affect ALA synthase and should be safe to use in patients with porphyria. Some caution is required, however, when applying results of animal studies to humans as different species may vary in their response to inducing agents.

There is currently considerable concern about the many adverse effects of anti-inflammatory agents. The elucidation of the biochemical basis of drug induced attacks of porphyria has meant that this particular adverse effect can be predicted and prevented. Hopefully this will also soon be true of some of the other adverse effects of these agents.

\section{References}

1 McColl K E L, Moore M R. The acute porphyrias-an example of pharmacogenetic disease. Scott Med $J$ 1980; 26: 32-40.

2 McColl K E L, Moore M R, Goldberg A. Porphyrin metabolism and the porphyrias. In: Hardisty $R$ M, Weatherall D J, eds. Blood and its disorders. Oxford: Blackwell Scientific, 1982: 577-601. 
3 Parikh R K, Moore M R. Effects of certain anaesthetic agents on the activity of rat hepatic delta-aminolaevulinate synthetase. Br J Anaesth 1978; 50: 1099-103.

4 Moore M R, McColl K E L, Goldberg A. Drugs and the acute porphyrias. Trends in the Pharmacological Sciences 1981; 2: $330-4$.
5 Bacq Z M, Capek R, Paoletti R, Renson J. Biotransformation $\square$ of drugs. In: Bacq $\mathrm{Z}$ M, ed. Fundamentals of biochemical pharmacology. Oxford: Pergamon, 1971: 603-4.

6 McColl K E L, Moore M R, Thompson G G, Goldberg A. Induction of delta-aminolaevulinic acid synthase in leucocytes of patients on phenytoin therapy-comparison with changes in rat hepatic tissue. Br J Clin Pharmacol 1980; 9: 327-31. 